\title{
The Role of Knowledge Management in Processing of Informational Uncertainty of Managers
}

*Researcher Ahmed Ghazi Mahdi, ** Researcher Luma Qays Raoof, \#Researcher Hatem Ali Ramadhan

*Ministry of Health, **Ministry of Higher Education, \#Ministry of Interior

DOI: $10.37648 /$ ijrssh.v10i04.006

Received:20 th August, 2020; Accepted:14th September, 2020; Published:01 ${ }^{\text {st }}$ October, 2020

\begin{abstract}
The current research aims to identify the importance of the role played by knowledge management in processing information uncertainty. This role has increased because of the dynamic nature of the contemporary business environment and the challenges that hinder the organization's ability to achieve its goals and continuity in work. The research problem refers to the extent to which managers are able to benefit from knowledge management in rationalizing their decisions through processing information uncertainty. The researchers adopted the analytical descriptive approach in the applied side of the research. The questionnaire was adopted as a main tool for collecting data, which was distributed to the members of the college of Isra, the total of (21) individuals. The statistical program (SPSS-v21) was also adopted in the introduction and analysis of research data, where the percentage of repetition, arithmetic mean, standard deviation, and coefficient of variation were adopted in the diagnosis of the reality and significance of the variables investigated, while the correlation coefficient of spearman and the simple linear regression were used in testing the hypothesis of research. The results were explained and discussed in the practical aspect of the research in detail. These statistical tools produced a number of results which confirmed the validity of the hypothesis from which the research began. Therefore, the researchers concluded that knowledge management is one of the main engines to assist the managers of the organization concerned with processing the lack of information. Therefore, it is recommended to consult the experiences of developed countries in this field and to benefit from their ideas in promoting knowledge in the local environment.
\end{abstract}

Key words : Knowledge Management, Informatics, Information, Managers, Business Organizations.

\section{INTRODUCTION}

Most contemporary business organizations seek to create added value for them and for all stakeholders, which in turn require the acquisition of information on all parties and processes related to their activities. Here, one can notice the importance of knowledge management as the body responsible for acquiring, storing and distributing knowledge on the human resources within the organization and its importance to ensure that it is not obsolete as compared to developments in the environment. Because of the rapid changes in the dynamic world and the business environment in particular, the organizations face an uncertain future with its various variables, which led to the emergence of the case of uncertainty, which is one of the challenges that hinder the organization from achieving its goals and address the competitive attacks that would lead to failure and exit from industry. Hence the main idea of the research as an attempt to 


\section{(IJRSSH) 2020, Vol. No. 10, Issue No. IV, Oct-Dec}

identify the role played by knowledge management in processing the lack of information among business managers. The scientific methodology for research can be summarized under the following subparagraphs :

1. Search problem : There is a lot of intellectual controversy in the writings of researchers on the effectiveness of knowledge management and its output knowledge itself, and this interaction is open to employ this knowledge in the face of the challenges generated by the environment in the creation of the case of certainty to make the right decision, which is expected to blur the realization of this role of knowledge management in processing the state of informational uncertainty associated with environmental dynamics. The main question is whether the Iraqi director, living in a developing environment, was able to employ knowledge management and its data to create a state of sufficient information to make sound decisions? The research problem can be expressed in the following questions:

- What level of knowledge management practices in the organization are being investigated.

- What is the level of uncertainty in the organization in question.

2. Importance of research : The importance of research is highlighted in the attempt to provide a
e-ISSN: 2249-4642, p-ISSN: 2454-4671

set of proposed solutions to address the problems experienced by the organization in the field of knowledge management and information uncertainty. Through reviewing the experiences of a number of developed countries in this field and previous Arab and foreign studies to benefit from their results to improve the application of these vital variables in the field of management. The resulting consequences will provide an opportunity to guide the Iraqi director on how to employ knowledge management processes in processing information uncertainties.

3. Research objectives : Diagnosis of the reality and importance of knowledge management and information uncertainty in the organization in question, as well as to identify the nature of the relationship and influence between them, and then come up with a set of conclusions and recommendations that would enhance knowledge in the field respondent.

4. Research model : The main purpose of the research model is to clarify the nature of the correlation and influence paths between the investigated variables and the most important results expected from them, as shown in the following diagram :

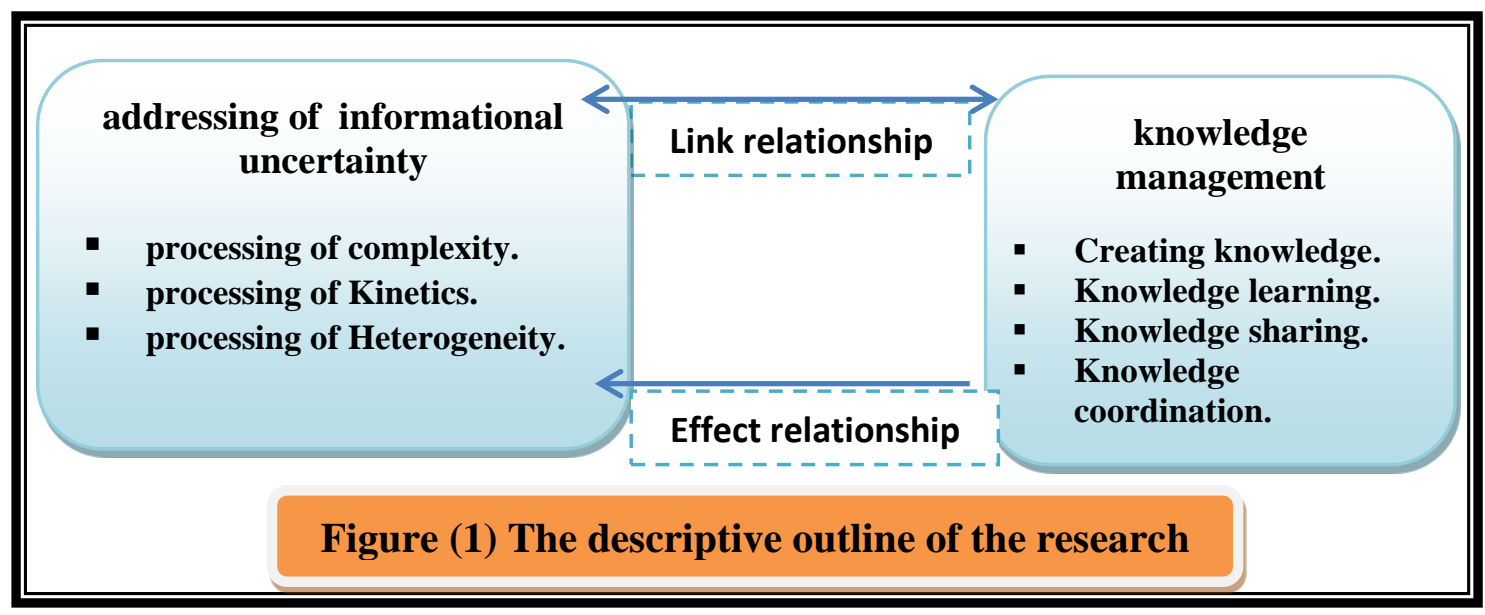


(IJRSSH) 2020, Vol. No. 10, Issue No. IV, Oct-Dec

5. The hypothesis of research : The research is based on a basic hypothesis which states: (there is a significant correlation and influence relationship between the knowledge management and the processing of information uncertainty in the organization).

6. Research methodology and data collection tool : The analytical descriptive approach was used to conduct the applied side of this research in order to comply with the main objectives that it seeks to achieve. The questionnaire was adopted as a main data collection tool, which was prepared based on a number of ready-made measurements and as noted in the theoretical sections.

7. Society and research sample : The education sector has been selected as the field of application . The College of Israa was chosen as a community for application because it is one of the leading Iraqi civil colleges . The sample of the study was damaged by the members of the college board (21) individuals . They are responsible for decision-making In the investigated college .

\section{KNOWLEDGE MANAGEMENT}

Identifying a rigorous concept of knowledge management is difficult because of divergent views and researchers' views. Knowledge is old, but its management is relatively modern, due to the emergence of a set of measures that can be used to measure its performance, as well as development in information technology, globalization and other factors (Tashkenti, 2018: 72). Knowledge management, focusing on the organizational dimension, is defined as the processes implemented by the organization to support its organizational and collective learning processes through influencing the behavioral and intellectual dimensions of its employees (Buheji at el, 2015: 154). It should be noted that this definition emphasizes the organizational aspect of knowledge management. In the same direction, it has been defined as generating the necessary knowledge through learning processes and disseminating them for use in the implementation of all organization operations (Tayeh \& Najjar, 2017 :7) . By clarifying the role of knowledge management in helping the organization to adapt to its external
e-ISSN: 2249-4642, p-ISSN: 2454-4671

environment, it has been defined as the tool which it depends on following developments that take place in the external environment and in a way that the organization can predict and reserve for achieving its goals (Gonzalez \& Martins , 2017 : 249) . In accordance with the decision-making approach, it is defined as the administration responsible for providing the necessary information to rationalize the current and future decision-making processes in a timely manner to exploit the opportunities available to the organization (Karim \& Dham , 2017 : 36) . This definition shows the importance of the role played by knowledge management in supporting the decisions of the organization and enhancing its ability to invest the resources available to it, this can be illustrated in the next definition, which defines knowledge management as the administration responsible for enhancing the organization's capacity to optimize the use of information, expertise, capabilities and intellectual skills of its human resources through diagnosis, generation, participation and sustainability (Oufkir at el, 2017:2). From another point of view, it is known as the official effort of the Organization to capture, collect, organize and store different types of knowledge in a manner that makes it ready to support decision processes within the organization through its participation among its employees (Shaman, 2018 : 404). In the cultural perspective, knowledge management has been defined as the culture of the organization by directing and managing the knowledge resources and information available to it with the best possible efficiency in order to achieve its objectives with the required efficiency (Wang at el, 2018 : 2). Having considered the previous definitions, knowledge management can be defined as a procedural definition for the purposes of the current research as the administration responsible for implementing the processes of creating, learning, sharing and coordinating the knowledge available to the organization to help it achieve its objectives in a manner that ensures its survival within its environment.

And on the importance of knowledge management for contemporary organizations : (Al-Kubaisi and Al-Hadithi , $2016: 8$ ) pointed to the importance of knowledge management by focusing on the elements of technology and human element and cultural factor and organizational structure and processes and their 
(IJRSSH) 2020, Vol. No. 10, Issue No. IV, Oct-Dec

role in enhancing the processes of innovation and creation of the organization and then improving their performance levels . (Bitkowska , 2016 : 32) agreed with the previous idea pointing out that most of the achievements of the organization are the result of the employment of knowledge possessed by its employees in its activities and functions, and thus constitute the knowledge possessed by the organization. The backbone of all the activities and tasks are carried out within the environment in which it operates (Gonzalez \& Martins , 2017 : 249) . It also contributes to helping the organization to attract intellectual capital, which plays an important role in reducing the costs of implementing the activities and tasks of the organization (Oufkir at el , $2017: 4$ ) . Therefore, most of the results that the organization can achieve in the development of its human resources and raise their
e-ISSN: 2249-4642, p-ISSN: 2454-4671

competence, skills and abilities in order to enhance their competitive advantage is due to knowledge management (Shaaban at el ,2018 :101). (Abd alRazzaq, 2018: 165) agreed with the former opinion as confirmed that knowledge management plays an important role in achieving and enhancing the satisfaction of the customers with which the organization deals by generating the added value, which in turn can be reflected in enhancing its market share compared with other organizations that work with it within the same field.

And the dimensions that could be adopted in the knowledge management study : Will focus on the most prominent operations, as there is a clear difference between the researcher and those interested in the study of knowledge management processes in the identification, and as shown in table (1) :

Table (1) Dimensions of knowledge management according to the orientations of some researchers

\begin{tabular}{|c|c|c|c|c|c|c|c|c|}
\hline \multirow[b]{2}{*}{$\begin{array}{l}\text { Researcher } \\
\text { \& Year }\end{array}$} & \multicolumn{8}{|c|}{ Extend knowledge } \\
\hline & $\begin{array}{l}\text { Diagnosis } \\
\text { of } \\
\text { knowledge }\end{array}$ & $\begin{array}{l}\text { Definition } \\
\text { of } \\
\text { knowledge } \\
\text { objectives }\end{array}$ & $\begin{array}{l}\text { Generating } \\
\text { knowledge }\end{array}$ & $\begin{array}{l}\text { Knowledge } \\
\text { storage }\end{array}$ & $\begin{array}{l}\text { Knowledge } \\
\text { organization }\end{array}$ & $\begin{array}{l}\text { Sustain } \\
\text { knowledge }\end{array}$ & $\begin{array}{l}\text { Knowledge } \\
\text { distribution }\end{array}$ & $\begin{array}{l}\text { Application } \\
\text { of } \\
\text { knowledge }\end{array}$ \\
\hline $\begin{array}{lr}\text { Heisig } & \text { \& } \\
\text { Vorbeck } & , \\
2001 & \end{array}$ & $*$ & $*$ & $*$ & $*$ & * & $*$ & - & - \\
\hline $\begin{array}{ll}\text { Tayeh } & \& \\
\text { Najjar } & \text {, } \\
2017 & \end{array}$ & - & - & $*$ & $*$ & - & - & $*$ & $*$ \\
\hline $\begin{array}{l}\text { Ammar } \\
2017\end{array}$ & - & - & $*$ & * & - & - & $*$ & $*$ \\
\hline $\begin{array}{l}\text { Johannessen } \\
\text {, } 2017\end{array}$ & $*$ & * & - & - & * & * & - & - \\
\hline
\end{tabular}

Source: Preparation of the researchers to the views of the researchers mentioned in the table above.

The model submitted by (Dilmaghani at el, 2015: 6) will be adopted in the study and interpretation of knowledge management in the practical aspect of this research, which includes four dimensions (creating knowledge, learning knowledge, sharing knowledge, and coordinating knowledge) so as to bring the environment closer to research with the Iraqi environment and thus will help to generalize the results for the current research . Knowledge Creation refers to the process of creating knowledge by seeking to create an organizational environment and culture that supports innovation processes and encourages innovation among individuals working for organization, thereby contributing to enhancing the levels of knowledge available to it (Buheji at el , 2015 : 155). Knowledge Coordination reflects the development of a series of procedures and mechanisms that specify the activities and functions that can be carried out by human resources when dealing with the knowledge available to the 
(IJRSSH) 2020, Vol. No. 10, Issue No. IV, Oct-Dec

organization in such a way as to ensure that there are no conflicts of interest when used (Bitkowska, 2016 : 34). While focusing on the Learning of Knowledge which includes the discovery of knowledge and follow-up developments that take place inside and outside the organization to ensure the acquisition of the knowledge necessary to generate the knowledge capital necessary to support the processes of creativity and innovation of its own (Shaaban at el 2018:103). With regard to Sharing of Knowledge, it refers to the transfer, dissemination of the knowledge available to the organization to ensure the exchange and transfer between its human resources at all organizational levels and to benefit from information technology in order to ensure the collective use of knowledge and make the most of it (Wang at el , 2018:2).

\section{INFORMATIONAL UNCERTAINTY}

Lack of information uncertainty is one of the important administrative challenges that have a significant impact on the performance of organizations in general and their managers in particular. Here we have a set of ideas and directions as an attempt to identify and define the most important conceptual dimensions related to it . Latakid has been defined by information and by psychological focus by (Difounzo \& Bordia, 1998).

As the psychological state, felt by the managers working within the organization, is the result of the uncertainty of the changes that may occur in the future (Kubaisi \& Almudu , 2015 : 52) either by focusing on the most important outcomes or outputs that can be obtained from the decision-making process. Informational uncertainty has been defined as situations and circumstances in which the administration is unsure of the events that will result from the decisions it makes in the future (Takeuchi at el , 2012 : 284). We note that the ex-strippers, despite the divergent trends of the researchers, share a point, which is the vagueness of future events that the organization will face. This is also consistent with the ideas of the definition, which referred to the lack of information that the state of uncertainty faced by the administration due to the state of uncertainty experienced by the variables of the environment and the public that constitute the boundaries of the organization (Sultan \& Akkar, 2013 : 70) . From a behavioral point of view, it was recognized as one of the motivational approaches adopted by the
e-ISSN: 2249-4642, p-ISSN: 2454-4671

organization to encourage its managers to follow developments in the variables affecting their operations to ensure that they are not obsolete (Junior \& Carvalho , $2013: 65)$. Informational uncertainty has also been defined as the risk facing the management of the organization due to the various differences and uncertainties that it now faces and the future directions it may face in its work (Vale \& Carvalho, 2016 : 94). Focusing on the strategic aspect of the organization, it was defined as the lack of information available to the administration regarding the alternatives of decisions it could take in achieving the strategy it seeks to accomplish (Hammadi and Ali, 2016: 45). In the same direction, it has been defined as the inability to predict changes that could occur in the environment surrounding the organization, complicating the decision-making processes undertaken by the organization (Johansen al el , 2016 :4). After examining the previous definitions, it is possible to define the theoretical information uncertainty for the purposes of this research as the case of the failure of the administration in dealing with information when making decisions due to the complexity of the variables of the external environment and dynamics and inconsistencies in their directions .

And the importance of informational uncertainty : It is necessary to emphasize the positive aspect of it, as it helps to guide and encourage the organization to collect a set of positive results with regard to its competitive position and market share in the industry within its borders (Ward \& Chapman , 2003 : 98). This will contribute to strengthening or generating a range of strategic options that contribute to helping the organization achieve its goals. Therefore, uncertainty is one of the catalysts for the human resources working within the organization to invent new methods and ways to meet the challenges that hinder their business (Migilinskas \& Ustinovicius, 2008: 790). It also encourages organizational learning processes that provide the capabilities and knowledge that ensure the organization's sustainable performance (Junior \& Carvalho, $2013: 65$ ).

Many researchers have confirmed that there are many types of informational uncertainties, but in general, most of them can be identified by technological uncertainty which reflects the lack of information possessed by the administration regarding how to 
(IJRSSH) 2020, Vol. No. 10, Issue No. IV, Oct-Dec

operate the electronic systems and programs within the organization (Magnani \& Montesi, 2010: 2). Knowledge uncertainty refers to the apparent lack of knowledge of a specific ritual related to the organization's operations and activities (Kubaisi \& Almudu , 2015 : 25) . As was the division of informational uncertainty into two types according to the environment in which the organization operates, internal information uncertainty includes lack of information on their functions, resources, structures and culture.

The external information uncertainty relates to the public and private external environmental information
e-ISSN: 2249-4642, p-ISSN: 2454-4671

that the organization deals with (Johansen al el, 2016 : 4-5). Information uncertainty was also divided into an uncertain situation indicating the inability to understand how to change the environmental situation surrounding the organization, and the effect uncertain resulting from the inability of managers to anticipate the consequences of changes of the previous type. The responsive uncertain indicates weak capacity to respond or take the necessary positions to meet external challenges (Al Saidi , 2017 : 257).

There is a range of dimensions that can be adopted in the study of informational uncertainty clarified most notably through table (2):

Table (2) The dimensions of information uncertainty according to the orientations of some researchers

\begin{tabular}{|c|c|c|c|c|c|c|c|c|}
\hline \multirow{2}{*}{$\begin{array}{l}\text { Researcher } \\
\text { \& Year }\end{array}$} & \multicolumn{8}{|c|}{ The dimensions of information uncertainty } \\
\hline & $\begin{array}{l}\text { Ignore } \\
\text { uncertainties }\end{array}$ & $\begin{array}{l}\text { Generating } \\
\text { knowledge }\end{array}$ & Interaction & confrontation & Kinetics & Hostility & Heterogeneity & Complexity \\
\hline $\begin{array}{l}\text { Takeuchi } \\
\text { at el, } 2012\end{array}$ & - & - & - & - & - & - & * & $*$ \\
\hline $\begin{array}{l}\text { Kubaisi } \\
\text { and } \\
\text { Almudu , } \\
2015\end{array}$ & $*$ & $*$ & * & $*$ & - & - & - & - \\
\hline \begin{tabular}{l}
\multicolumn{2}{l}{ Hammadi } \\
$\& \quad$ A, \\
2016li
\end{tabular} & $*$ & - & - & - & $*$ & $*$ & $*$ & - \\
\hline $\begin{array}{ll}\text { SilvaI \& } & \text { Ferrira, } \\
2017 & \end{array}$ & - & - & - & - & $*$ & - & $*$ & $*$ \\
\hline
\end{tabular}

Source: Preparation of the researchers to the views of the researchers mentioned in the table above.

The Johansen al el (2016) model will depend on the study of the dimensions of informational uncertainty in this research to be consistent with the main objectives that it seeks to achieve, namely; the first dimension (complexity) refers to the diversity and multiple variables and elements in the environment surrounding the organization, making it difficult to enumerate and determine the most important directions (Takeuchi at el , 2012 : 284). The second dimension (kinetic) refers to the dynamic changes that occur in the phenomena surrounding the organization and the variables affecting them, which are difficult to predict and deal with (Hammadi and Ali , 2016 : 45) . The third dimension (heterogeneity) reflects the breadth of research areas in which managers can look at environmental factors, creating chaos and inconsistency between the information available to the administration (SilvaI \& Ferrira, 2017 : 13).

By focusing on the nature of the relationship between knowledge management and information uncertainty, it has been noted that the generation of new knowledge, which represents one of the processes of knowledge management, results in informational uncertainty as a natural result of the existence of a large body of information to be dealt with (Takeuchi at el , $2012: 284)$. On the other hand, it has been noted that information uncertainty is one of the motivations that drives knowledge management towards the 
(IJRSSH) 2020, Vol. No. 10, Issue No. IV, Oct-Dec

creation of new information to meet the shortage in the organization and thus address the problem of information uncertainty (Vale \& Carvalho, 2016 : 95)

. Based on this, it is clear that there is a reciprocal relationship between knowledge management and information uncertainty. Based on this again, the main hypothesis emerged from the research mentioned in the introduction paragraph.

\section{ANALYSIS OF THE RESULTS AND INTERPRETATION}

In this section, the researchers attempt to diagnose the reality of the investigated variables and the relative importance of their sub-dimensions as well as to find the relationship of correlation and influence while in the form that helps him to discuss and interpret and then test the validity of the main hypothesis contained in this research as in the following paragraphs:
e-ISSN: 2249-4642, p-ISSN: 2454-4671

4.1: Diagnosis of the reality of the variables investigated and the relative importance of their sub-dimensions

Table (3) shows the most prominent results produced by the statistical tools used in diagnosing the reality and importance of the variables being investigated (the percentage of the agreement has been compared to the standard of the agreement). The mean which is interpreted as follows: \{If the value varies between 1.80 - 1.80 means that the variable is very weak; between 1.81 - 2.60 variable weak; between 2.61 3.40 variable around the mean neutral; between 3.41 - 4.20 variable high, between 4.21 - 5 variable too high $\}$. The standard deviation has been interpreted as follows $\{$ If its value is below 0.80 , it reflects a high correlation between the answers; if its value is between 0.80 - 0.90, the harmony is good; but if it is above 1.0, this is an acceptable harmony . The coefficient of variation measures the dispersion between the studied phenomena, the lower the percentage, the smaller the dispersion. The results are as follows :

Table (3) Diagnosis of the reality and importance of the variables investigated

\begin{tabular}{|c|c|c|c|c|}
\hline Variables & $\begin{array}{l}\text { Percentage } \\
\text { of agreement }\end{array}$ & $\begin{array}{l}\text { Arithmetic } \\
\text { mean }\end{array}$ & $\begin{array}{l}\text { Standard } \\
\text { deviation }\end{array}$ & $\begin{array}{l}\text { Coefficient } \\
\text { of variation }\end{array}$ \\
\hline \multicolumn{5}{|c|}{ Variable knowledge management } \\
\hline Creating knowledge & $\% 83$ & 3.7 & 0.72 & 0.19 \\
\hline Knowledge learning & $\% 92$ & 4.2 & 0.65 & 0.15 \\
\hline Knowledge sharing & $\% 89$ & 3.8 & 0.68 & 0.18 \\
\hline Knowledge coordination & $\% 79$ & 3.1 & 0.83 & 0.27 \\
\hline $\begin{array}{ll}\text { Total } & \text { knowledge } \\
\text { management } & \\
\end{array}$ & $\% 86$ & 3.7 & 0.72 & 0.20 \\
\hline \multicolumn{5}{|c|}{ Variable processing of informational uncertainty } \\
\hline Processing of complexity & $\% 83$ & 3.3 & 0.81 & 0.25 \\
\hline Processing of Kinetics & $\% 89$ & 3.7 & 0.73 & 0.20 \\
\hline $\begin{array}{l}\text { Processing } \\
\text { heterogeneity }\end{array}$ & $\% 85$ & 3.4 & 0.78 & 0.23 \\
\hline
\end{tabular}




\begin{tabular}{|l||l||l|l||l||}
\hline $\begin{array}{l}\text { Total information } \\
\text { uncertainty }\end{array}$ & $\% 86$ & 3.5 & 0.77 & 0.22 \\
\hline \hline $\mathrm{n}=21$ & & \\
\hline
\end{tabular}

Source: Preparation of the researchers based on the results of the analysis.

$++++++++++$

1. Variable knowledge management : Note from table (3) that the knowledge management variable includes four dimensions. Within the framework of the results of the analysis, it is clear that the percentage of agreement on this variable was $(86 \%)$, which is higher than the standard ratio of the agreement $(66.7 \%)$. These results clearly reflect the organization's reliance on knowledge management in the implementation of the activities and tasks it undertakes in order to achieve the objectives it seeks, whether through the creation and learning of knowledge or by ensuring its participation among its human resources and then coordinating them in the best possible form at organizational levels inside them. The value of the arithmetic mean confirmed this result at (3.7), which is higher than the mean (3). It indicates a knowledge management variable and a high level in the investigated organization. The value of the standard deviation was $(0.72)$ and it reflects the high harmony between the responses of the sample members to the direction of the paragraphs of this variable. This result confirms the value of the difference coefficient (0.26) . At the sub-dimension of the knowledge management variable, it came after learning the knowledge in the first rank with a mean value of (4.2). After sharing the knowledge, it came in second place with a mean of (3.7), after creating the knowledge at the third rank with a mean of
(3.7) after formatting the last rank with an arithmetic value (3.1).

2. Variable processing of informational uncertainty : The variable of non-information processing was measured in three dimensions as shown in table (3). The percentage of the agreement reached (0.86) which is very good and higher than the value of the standard agreement. Therefore, this result confirms that the organization in question is working to provide all the facilities, software and capabilities necessary to deal with cases of uncertainty that hinder the decision-making process by its managers and in a manner that ensures the achievement of the desired goals and thus ensure the entitlement of work within them. The value of the arithmetic mean for this variable is (3.5), which is the highest mean arithmetic mean and confirms the high presence of the processing of informational uncertainty in the organization in question. While the standard deviation $(0.77)$ was a reflection of a high correlation between the responses of the sample members to the paragraphs of this variable , the difference coefficient (0.22), and at the subdimension level of the variable for processing information uncertainty, it came after the processing of kinetics in the first place with the value of a mean (3.7), followed by the processing of heterogeneity ranked second with the value of the mean (3.4), after processing the complexity at the last rank with a mean value of (3.3). 
4.2: Analysis of the correlation between knowledge management and processing information uncertainty Table (4) shows the correlation coefficients of the spearman coefficient between knowledge management and processing of information uncertainty and their subdivisions. The results were as follows:

Table (4): Relationship between knowledge management and processing information uncertainty

\begin{tabular}{|c|c|c|c|c|}
\hline $\begin{array}{l}\text { processing informational } \\
\text { uncertainty } \\
\text { Knowledge management }\end{array}$ & $\begin{array}{l}\text { processing } \\
\text { of } \\
\text { complexity }\end{array}$ & $\begin{array}{l}\text { processing of } \\
\text { Kinetics }\end{array}$ & $\begin{array}{l}\text { processing of } \\
\text { heterogeneity }\end{array}$ & $\begin{array}{l}\text { the total of the } \\
\text { processing } \\
\text { informational } \\
\text { uncertainty }\end{array}$ \\
\hline Creating knowledge & $* * 0.63$ & $+* * 0.61$ & ***0.71 & $* * 0.65$ \\
\hline Knowledge learning & $7 * 0.73$ & $\overline{* * * 0.57}$ & $* * 0.57$ & $7 * 0.62$ \\
\hline Knowledge sharing & *0.44 & $* * 0.53$ & $* * 0.64$ & "**0.54 \\
\hline Knowledge coordination & $* * 0.51$ & $* * 0.63$ & $* * 0.71$ & $* * 0.62$ \\
\hline $\begin{array}{l}\text { Total knowledge management } \\
\text { variable }\end{array}$ & $* * 0.60$ & $* * 0.57$ & $* * 0.64$ & $* * 0.60$ \\
\hline
\end{tabular}

Source: Preparation of the researchers based on the results of the analysis.

** The correlation with special significance at level 0.01

* The correlation has special significance at level 0.05

In table 4, the total correlation coefficient between the knowledge management variable and the information uncertainty coefficient was $(0.60 * *)$, a positive relationship at a significant level $(0.1)$. These findings illustrate the important role that knowledge management plays in helping managers who are engaged in the organization to be highly professional in making decisions within a limited amount of information available to them. It also shows the importance of the relationship between knowledge management and the processing of informational uncertainty through its four dimensions, as the relationship between them and the variable response ( ،**0.54 ،**0.62 ،**0.65 $* * 0.62)$ respectively, all of which have positive relations with special significance at (0.01). Therefore, these results are heard with the acceptance of the main hypothesis of the research, which stated (there is a significant correlation and influential relationship between the knowledge management and the processing of information uncertainty in the organization).

\section{3: Analysis of the impact of knowledge management in the processing of informational uncertainty}

Table (5) shows the results of the relationship analysis between the dimensions of knowledge management in the processing of information uncertainty in the organization investigated using the simple linear regression coefficient as follows:

Table (5) Results of the impact of the dimensions of knowledge management in the processing of informational uncertainty

\begin{tabular}{|c|c|c|c|c|c|c|}
\hline Independent variables & $\mathbf{a}$ & B & $\mathbf{R}^{2}$ & Calculated F & \multicolumn{2}{|c|}{ Moral level } \\
\hline Creating knowledge & 0.41 & 0.76 & $\% 42$ & 15.54 & 0.01 & There is an effect \\
\hline Knowledge learning & 0.39 & 0.84 & $\% 39$ & 19.37 & 0.01 & There is an effect \\
\hline Knowledge sharing & 0.43 & 0.66 & $\% 29$ & 13.76 & 0.01 & There is an effect \\
\hline "Knowledge coordination & (0.38 & (0.81 & \%\%38 & 18.91 & (20.01 & There is an effect \\
\hline knowledge management & 0.41 & 0.77 & $\%$ \%36 & 16.9 & 0.01 & There is an effect \\
\hline
\end{tabular}

Source: Preparation of the researchers based on the results of the analysis. 
(IJRSSH) 2020, Vol. No. 10, Issue No. IV, Oct-Dec

Table (5) shows that the calculated value of (f) is (16.9), which is greater than its tabular value at a significant level (0.01) and with confidence limits $(99 \%)$, These results reflect the impact of knowledge management in processing informational uncertainty. The value of the constant was $(a=0.41)$ which means that there is a processing informational uncertainty of $\% 41$ even if knowledge management is zero. The value of $(B=0.77)$, this means that changing knowledge management by one unit will result in a change in the processing of information uncertainty by (0.77). The value of (R2) was (0.36), this means that $(36 \%)$ of the variance in the processing of informational uncertainty is an interpreted variance by the knowledge management that entered the model, and that only (64\%) is an explained variance of factors that did not enter the regression model. The number of regression models for the sub-dimensions of knowledge management, which achieved significant effect, reached (4) samples out of (4), i.e., (100\%) of total affective relationships. Since the overall knowledge management has had a significant impact on the processing of informational uncertainty, there is a justification not to reject the main hypothesis of research and that (there is a significant correlation and influence relationship between the knowledge management and the processing of information uncertainty in the organization).

\section{CONCLUSIONS RECOMMENDATIONS}

AND

The organization relies heavily on knowledge in the implementation of its functions through the creation
e-ISSN: 2249-4642, p-ISSN: 2454-4671

and learning and then share among its human resources to achieve better coordination between them and then achieve the desired goals, and should therefore take into account the need to increase the investment in the field of knowledge management to follow up all the developments that occur in this process. Thus, strengthening its competitive position in the sector in which it operates, the organization is keen to address information uncertainty by processing the dynamics, complexity and heterogeneity of the changes that occur in the surrounding environmental phenomena. So it is necessary for the organization to build modern databases that provide the administration with all the information it needs in a timely manner. The results of the correlation analysis have confirmed that knowledge management and its secondary dimensions play an important role in enhancing the ability of managers in the organization to address information uncertainty in decision making. Therefore, a set of standards and rules that define how to enhance the interaction between human resources at all organizational levels facilitate the exchange of knowledge among them. As shown by the results of the simple linear regression analysis, knowledge management contributes significantly to processing information uncertainty in the organization investigated through its four dimensions. Therefore, the organization should support these dimensions by reviewing the experiences of developed countries in this field in order to ensure that they deal with the accuracy required with all cases of uncertainty that hinder the decision-making process within them.

\section{SOURCES}

1. Abdul Razzaq, Jannan Sadek (2018) The use of electronic services at the Higher Institute of Telecommunications to reduce the gap in the knowledge management of employees , Al Mustansiriya Journal of Arab and International Studies, No. 61, pp. 161-182.

2. Ammar, Hamoud (2017) The impact of knowledge management systems on marketing innovation: A field study in a sample of Algerian institutions, PhD, Faculty of Economic Sciences, Commercial Sciences and Management Sciences, Qasidi University, Marbah and Argla.

3. Al-Kibaisi, Salah al-Din Awad \& Al-Mado, Alaa Abdul Karim Ghalib (2015) Impact of uncertainty management strategies in organizational change strategies: A comparative study in Zain and Asia Cell Communications, Journal of the Baghdad College of Economics, University, No. 46, pp. 45-74. 
4. Al-Kibaisi, Salah al-Din Awad \& Al-Hadithi, the sun is enhanced by Iskandar (2016) The Impact of Key Elements of Knowledge Management in Strategic Performance: A Field Study of a Sample of Private Banks in Baghdad, Journal of Economic and Administrative Sciences, Faculty of Management and Economics - University of Baghdad, Issue 99, Volume 23, pp. 1-23.

5. Al seydy, Yarab Adnan (2017) Analysis of the content of the uncertainty (nature and management) within two schools of strategic thinking (theoretical perspective), Journal of Economic and Administrative Sciences, Faculty of Management and Economics - University of Baghdad, Issue 99, Volume 23, pp. 253-274.

6. Bitkowska , Agnieszk (2016) Knowledge management vs business process management in contemporary enterprises, journal of Economics and Management, Volume 8 - Issue 2 : pp31-37.

7. Buheji , Mohamed \& Al-Hasan, Said \& Thomas, Brychan \& Melle, Denis (2015) Knowledge Management's Influence on Government Organisations' Innovativeness , journal of Management and Organizational Studies , Vol. 2, No. 1 : pp153-165.

8. Dilmaghani, Mitra \& Fahimnia, Fatima \& Ardakan, Mohammad Aboyee \& Naghshineh , Nader (2015) Function of knowledge culture in the effectiveness of knowledge management procedures: A case study of a knowledge-based organization, journal of Webology, Volume 12, Number 1 : pp1-21.

9. Hammadi, Aintisar Eabbas \& Ali , Lubna Qahtan Mohammed (2016) Effect of strategic flexibility and environmental uncertainty in regulatory health: field research in a number of Iraqi industrial companies , Danner Journal, Issue 8, pp. 45-71.

10. Gonzalez, Rodrigo Valio Dominguez \& Martins , Manoel Fernando (2017) Knowledge Management Process: a theoretical-conceptual research , journal of Gest. Prod., São Carlos , v. 24, n. 2, p. 248-265.

11. Johansen, Agnar \& Eik-Andresen, Petter \& Landmark, Andreas Dypvik \& Ekambaram, Anandasivakumar \& Rolstadås , Asbjørn (2016) Value of Uncertainty: The Lost Opportunities in Large Projects , journal of administrative sciences, vol 6 , no $11:$ pp1-17.

12. Johannessen, Jon-Arild (2017) Knowledge management in future organizations, journal of Problems and Perspectives in Management, Volume 15, Issue 2 : pp 306-318.

13. Junior, Roque Rabechini \& Carvalho, Marly Monteiro de (2013) Understanding the Impact of Project Risk Management on Project Performance: an Empirical Study, J. Technol. Manag. Innov, Volume 8, pp 64-78.

14. Karim, Salah al-Din Awad \& Dham, Abdul Sattar Ibrahim (2017) Competitiveness of business organizations according to the role of knowledge management and customer orientation: comparative survey study in Iraqi business organizations, Journal of Baghdad College of Economic Sciences, University, Issue 50, pp. 2768.

15. Magnani, Matteo \& Montesi, Danilo (2010) A Survey on Uncertainty Management in Data Integration , Journal of Data and Information Quality, Vol. 2, No. 1 : pp 1-33.

16. Mertins, K. \& Heisig P. \& Vorbeck J.(2001) Knowledge Best Practice In Europe, Springer Verlag Berlin, Heidelbery,Germany . p : 28.

17. Migilinskas, Darius \& Ustinovicius, Leonas (2008) Methodology of risk and uncertainty management in construction's technological and economic problems , journal of Vilnius Gediminas Technical University , vol $11:$ pp789-795.

18. Oufkir , Latifa \& Fredj, Mounia \& Kassou , Ismail (2017) Performance Measurement for Knowledge Management: Designing a Reference Model , Journal of Organizational Knowledge Management , Vol. 2017 : pp1-13.

19. Shaaban, Abdul Karim Hadi \& Moussa, Khansa Abdul Adel \& Jubouri, Ali Jassim Obaid (2018) Knowledge Management Processes and their Impact on Building Intellectual Capital: An Applied Study in the Faculty of Management and Economics, University of Kufa , Journal of Islamic College University, Issue 47: pp. 93122.

20. Shaman , Sinai (2018) Knowledge Management and its feasibility and ways of developing it: A case study of the Central Library at the University of Sulaymaniyah , Journal of Professor, No. 224, Vol. 2 , pp. 399414. 
21. Silva , Adilson . Aderito \& Ferrira , Coelho Martins Ferreira (2017) Uncertainty, Flexibility and operational performance of companies : Modelling from the perspective of managers, Mackenzie Management Review , vol 18 , no $4:$ pp12-38.

22. Sultan, Wafa Ali \& Akkar, Zainab Shalal (2013) Sources of environmental uncertainty and coping strategies: An applied study in the General Electricity Company - Basrah Governorate , Basrah Studies Journal, 8th Year, Issue 16, pp. 86-116.

23. Takeuchi, Riki \& Chen, Zhijun \& Cheung, Siu Yin (2012) Applying Uncertainty Management Theory To Employee Voice Behavior : An Integrative Investigation , journal of Personnel Psychology , vol 65 : pp 283 323.

24. Tashkenti, Zakih bint Mamdouh Qari Abdullah (2018) Knowledge Management The importance and extent of application of its operations from the point of view of the directors of departments and administrative supervisors in the Department of Education and Education in Makkah and Jeddah , Master Thesis, Faculty of Education, Umm Al-Qura University.

25. Tayeh, Mohamed Ibrahim \& Najjar, sabah majid (2017) Effect of Knowledge Management Processes on Performance of Immunization Service: An application of the application in the National General Insurance Company, Journal of Accounting and Financial Studies Volume 38, Issue 38, pp. 1-28.

26. Vale , Joрo Walter Saunders Pacheco do \& Carvalho, Marly Monteiro de (2016) Risk and uncertainty in projects management: literature review and conceptual framework , Project Management Portfolio : pp 94120.

27. Wang, Peng \& Zhu, Fang-Wei \& Song, Hao-Yang \& Hou , Jian-Hua \& Zhang, Jin-Lan (2018) Visualizing the Academic Discipline of Knowledge Management, journal of Sustainability, vol 10, no 682 : pp1-28.

28. Ward, Stephen \& Chapman, Chris (2003) Transforming project risk management into project uncertainty management , International Journal of Project Management, vol 21 : pp 97-105. 